\title{
Negotiating Problems of Practice in Research-Practice Design Partnerships
}

\author{
WILLIAM R. PENUEL \\ University of Colorado Boulder \\ CYNTHIA E. COBURN \\ Northwestern University
}

DANIEL J. GALLAGHER

Seattle Public Schools

This chapter focuses on how researchers and practitioners negotiate the focus of their joint work within design-based implementation research (DBIR). Studying and facilitating successful negotiation of the problems that become the focus of work and the search for solutions is important for developing DBIR, because of its commitment to focusing on persistent problems of practice from multiple stakeholders' perspectives. Case studies of two different research-practice partnerships provide a context for exploring two different perspectives on negotiation. In one case study, the notion of partnerships as forms of cultural exchange across institutional boundaries that differ with respect to goals, norms, and practices is used to analyze a design partnership focused on repurposing curriculum units in elementary science. In the second case study, the concept of framing as developed in social movement theory is used to illuminate issues of status and authority within a partnership between a district and researchers. The chapter concludes by describing the contributions of each perspective to an understanding of how teams jointly negotiate the focus of their work and by providing some recommendations for how teams can do so successfully. 


\section{NEGOTIATING PROBLEMS OF PRACTICE IN RESEARCH-PRACTICE DESIGN PARTNERSHIPS}

In this chapter, we develop conceptual frameworks for understanding how researchers and practitioners negotiate the focus of their joint work. Understanding how researchers and practitioners decide upon the focus and organization of joint work is important to the development of DBIR as an approach to research because the first principle of DBIR is that it should focus on jointly negotiated, persistent problems of practice (Penuel, Fishman, Cheng, \& Sabelli, 2011). We offer two different approaches to analyzing these negotiations: cultural exchange theory and frame theory. We illustrate each framework with a case example to illustrate aspects of negotiation in partnerships that the framework helps to illuminate, as well as what aspects are put into the background. Together, these frameworks and analyses highlight the ways that authority, status, and cultural norms of researchers and practitioners each influence how partnerships define problems and the kinds of strategies they pursue to address those problems.

Our chapter also outlines some strategies for teams to use to form mutualistic research-practice partnerships that could be refined and tested in future design-based implementation research. These practical methods represent an area of future research and development that would be aimed at improving the likelihood that researchers and practitioners might be able to jointly negotiate a focus and organization to their work that builds knowledge that is usable within an expanded system that positions researchers and practitioners as partners in educational change.

\section{RESEARCH-PRACTICE PARTNERSHIPS AS TRADING ZONES}

We find a particularly relevant metaphor for understanding cultural exchange in research-practice partnerships within the cultural anthropology writings of Galison (1997), who proposed that sites of collaboration can be imagined as trading zones. These are social spaces where people can debate and exchange ideas, and they are also material spaces were people engage in various forms of "place-making": building collaboratories, creating new types of organizations, and organizing coalitions for action or reform.

A core premise of the idea of the trading zone is that its participants occupy distinct and partly autonomous cultures. Because of this fact, a key task for participants in any trading zone is to establish a basis for how they will work together. According to Galison (1997):

Two groups can agree on rules of exchange even if they ascribe utterly different significance to the objects being exchanged; 
they may even disagree on the meaning of the exchange process itself. Nonetheless, the trading partners can hammer out a local coordination despite vast global differences. In an even more sophisticated way, cultures in interaction frequently establish contact languages, systems of discourse that can vary from the most function-specific jargons, through semi-specific pidgins, to full-fledged creoles rich enough to support activities as complex as poetry and metalinguistic reflection. (p. 783)

Other theorists, largely drawing on cultural-historical activity theory, have termed the kind of organizing activity in which these pidgins and creoles emerge as "boundary work," to call attention to the ways that people at the intersection of two different subcultures coordinate work and sometimes create new forms of social practice, that is, linked activities with distinct norms, tools, and rules for thinking, speaking, and acting together (Engeström, Engeström, \& Karkkainen, 1995; Star \& Griesemer, 1989; Wenger, 1998). In addition to creating ways of speaking with one another, this boundary work also frequently entails the creation of shared procedures and interpretations of objects and actions as a means of facilitating joint work.

In education, a common strategy for launching partnerships is to engage in co-design (Penuel, Roschelle, \& Shechtman, 2007), where, teachers and researchers come together to either adapt or create new curriculum materials or technologies. Typically, co-design teams must invent new formats for working together, because outside the co-design context, the more usual division of labor involves researchers "designing" while teachers "test" and "implement." Both groups have to find their way into the work of co-design, meaning the roles feel unfamiliar, and norms and procedures for inducting each partner into the work have to be established. Importantly, both groups tend to remain semi-autonomous: teachers continue to teach, and researchers continue to conduct research outside the space of the trading zone itself. Thus, each group maintains its primary institutional commitments and cultural practices outside the partnership, even if these are altered somewhat by the partnership.

Co-design frequently requires the participation of people who are able to span the boundaries of the two communities and who develop expertise in aligning practices across different communities (Akkerman \& Bakker, 2011; Beach, 2003). For example, to facilitate mutualistic exchange between researchers and practitioners, the governance processes within the SERP Institute (Donovan, Snow, \& Daro, 2013) call for employing a lead team comprised of different stakeholders for defining problems, which in turn charters design teams tasked with coming up with solutions to those problems. In addition, SERP relies on people who span the 
boundary between research and practice, including its leaders and staff. Their roles are to serve as a go-between for practitioners and researchers, translate different needs and concerns of the two groups, and bring the two into alignment. The role of boundary-spanners is critical because they help to translate the kinds of languages hat develop within partnerships to people outside the partnership, so that the work of the partnership itself can have a broader impact beyond its most active participants.

\section{THE BELLEVUE-UNIVERSITY OF WASHINGTON PARTNERSHIP AS A} TRADING ZONE

To illustrate how this metaphor can apply to a research-practice partnership, we draw on evidence from a case study of the Bellevue (WA) public schools and researchers at the University of Washington. In this partnership, a team of researchers, district staff, and teachers repurposed a widely used kit-based science curriculum unit; teachers then enacted the unit, and a design team studied its impact and made revisions on the basis of what they learned. The first author led the case study of this partnership, and the third author was a district leader within the partnership.

The case study was part of a larger, comparative study of three different partnerships. Data collection included interviews with key members of the partnership, including district officials, subject matter coaches, teachers, and research team members. We also conducted classroom observations of classrooms that were part of this partnership and two interviews with each of the classroom teachers about their experiences in designing or enacting the curriculum, or both.

In the early 2000s, the superintendent of the school district sought out John Bransford, the lead author of a National Research Council volume, How People Learn (HPL), which synthesized current science related to teaching and learning school subjects like science and mathematics (Bransford, Brown, \& Cocking, 1999). The superintendent proposed the first activity that the district and Bransford's team might pursue together, an "audit" of the district's new online core curriculum. By audit, the superintendent intended to have Bransford's team lead an external review of the district's curriculum that analyzed how well it aligned to the principles for designing learning environments outlined in HPL.

After spending time in elementary classrooms as part of the audit, Bransford's team concluded that the district-adopted Full Option Science System (FOSS) curriculum as implemented in these classrooms was not incorporating key elements of the HPL framework. His team argued before the superintendent that science classrooms were far less learner-centered than called for in the HPL framework, and that classrooms could not be characterized as "environments [that] attempt to 
help students make connections between their previous knowledge and their current academic tasks" (National Research Council, 1999, p. xvi). The superintendent suggested that the district could start anew with a different curriculum, but the team negotiated a joint decision to work toward repurposing a FOSS unit as a first step to improving the science curriculum. District staff argued with the superintendent that it was not fiscally responsible to drop such an expensive curriculum without first trying to use some of the materials and resources that the units offer. In discussion with one another, researchers and practitioners also came to agree that the existing FOSS units were worth investing in repurposing to better meet the needs of the district's goals for student learning.

As is often the case with negotiations around boundary objects, the participants in the partnership came from different subcultures and did not share the same view about what needed improvement. They shared neither the same interpretations of $H P L$ as a framework, nor the same interpretations of the FOSS units that were the object of design, two key boundary objects within the partnership. With respect to the FOSS units, from the researchers' perspective, one of the units the team decided to redesign did not promote enough deep inquiry into student-generated questions. In addition, to researchers, these topics seemed disconnected from any "big ideas" in science. For teachers, a problem with the existing unit was that it was repetitive and did not provide a lot of room for student thinking or idea development. In addition, teachers felt that the topics were not relevant to their students' lives. Researchers and teachers agreed to work on two areas that both saw as needing improvement: increasing inquiry into student-generated questions and increasing relevance. These areas would become targets for which the research team developed instruments to measure the impacts of the repurposed units on student learning. A third goal held in common, reducing the focus to a few big ideas and one set of organisms, also became key to the repurposing effort.

Once they established goals for their work together, the team needed to engage in additional boundary work to coordinate the work of improving or repurposing the curriculum unit. Joint meetings to review the materials and try and come up with new designs did not work. The group could not come to an agreement as to the key student activities of the unit. Bransford proposed that-for a period, at least-the researchers and district staff work separately on revised designs for the unit, and then come back to present their new designs to each other. The school district used the findings of the curricular audit to guide their revisions, while the University of Washington team worked more toward creating a unit based on an approach they had used many times before to organize problem-based learning in other domains, such as mathematics 
(see Schwartz, Lin, Brophy, \& Bransford, 1999). After two months, the two groups came back together to share their new curricula, but each group saw something different in what the other group had produced. From the researchers' perspective, there remained limited evidence of a driving purpose; the researchers advocated for the adoption of their problem-based approach, and they got the team to agree to adopt their approach. At the same time, the district was concerned about a key choice the researchers had made about the unit. The unit called for the study of a single organism, and the researchers chose a fish. The district staff made the researchers select a different organism from fish, noting it would be impractical to provide fish to so many classrooms as an organism to study.

At this point, the mathematics coach from the district, who had been instrumental in creating the version of the unit for the district, formally crossed the boundary from school district staff member to become a graduate student in the university program where John Bransford was a faculty member. She continued to work on the grant and was a hub of communication between the teams. Throughout the fall, she created drafts of the curriculum, and the UW team would help her flesh out these ideas at meetings. She was pragmatic in her curriculum design, using her teacher perspective to keep the curriculum realistic, while using the learning scientist perspective to inform principles of the design. Some elements of the school district redesign were retained, including their "idea journal," which helped students monitor their thinking and learning over time. When the team agreed the curriculum was ready to be piloted, she called on two teachers in the district she had worked with in the past, who she knew had been interested in being the pilot teachers for this unit, along with an additional teacher that the district chose.

As part of the design work that ensued, a pidgin language that blended Bransford's labels for the steps in his "challenge-based learning cycle" and national science inquiry standards familiar to teachers (National Research Council, 1996, 2000) emerged. Bransford's labels captured key elements of the cycle: "Challenge" (presenting students with the key problem or task of the unit), "Initial Ideas" (eliciting students' initial response to the challenge), "Investigation" (teacher- and student-designed investigations related to the challenge), "Research" (student investigations in books and on the Web related to the challenge), and "Go Public" (presentations of findings). In an interview with our research team, one of the teachers engaged in the design process, highlighted the ways that students might learn about specific aspects of the inquiry process as key to what students should learn from participating in the activities of the repurposed unit. She named asking questions, planning investigations, negotiating with group members about the direction of inquiry, writing 
conclusions, and communicating results. In highlighting these aspects, this teacher's constructions of the purpose resonated strongly with those of the collaborative design team and with discipline-specific goals and assessments for student learning promoted by her district. At the same time, there was evidence in the way that she and other teachers talked about the purposes of the unit that would have resonated more strongly with other teachers than with researchers. For example, she spoke about the unit helping students take more "ownership" of the unit and of the "hands-on" nature of the unit being beneficial to students. Over time, the researchers began to talk about "ownership" as well, recognizing that a key benefit for students was that the curriculum promoted greater student agency and purpose.

The emergence of a hybrid language for describing the purpose and structure of the units developed by the partnership is an indicator of the emergence of a productive trading zone within the partnership, and it illustrates one aspect of the utility of the trading zones concept for analyzing the negotiation of problems of practice and their solution within design-based implementation research. In particular, it directs attention of researchers toward the hybrid or "pidgin" in representations of practice, as opposed to fidelity to researchers' language, in studies of implementation. This kind of hybrid language and practice signals the ways that the designs reflect not just researchers' conceptions of how to organize instruction, but also practitioners' conceptions.

\section{FRAMING IN RESEARCH-PRACTICE PARTNERSHIPS}

While cultural exchange theorists highlight the challenges involved in collaboration across different cultural worlds, they provide less insight into the microprocesses by which deliberation, negotiation, and persuasion unfold. Nor do they attend to the role of status and authority that comes into play when negotiation occurs in cross-role or cross-institutional groups (Coburn, Bae, \& Turner, 2008; Coburn, Honig, \& Stein, 2009). Frame analysis provides conceptual tools for understanding this aspect of negotiation between researchers and practitioners in the context of partnership work.

Frame analysis provides a way to understand how ideas are produced and invoked to mobilize people to action (Snow \& Benford, 1988; Snow, Rochford, Worden, \& Benford, 1986). Developing a course of action, making a policy, or developing an intervention requires that individuals and groups explicitly or implicitly identify a problem to be solved and link that problem to a solution. How a particular problem is defined or "framed" is crucial, for it assigns responsibility and creates rationales that authorize some solutions and not others (Benford \& Snow, 2000; 
Schneider \& Ingram, 1993). The framing of problems within researchpractice partnerships is especially critical to reorganizing the relations between research and practice within design-based implementation research, because the frames negotiated explicitly name particular groups of researchers or practitioners as responsible for designing and implementing solutions.

The work of framing is social and interactive, constituted by two related processes: frame alignment and resonance. Frame alignment refers to the actions taken by those who produce and invoke frames in order to connect these frames with the interests, values, and beliefs of those they seek to mobilize (Snow, et al., 1986; Williams \& Kubal, 1999). Individuals and groups attempt to construct ways of framing the problem that provide "conceptual hooks" (Zucker, 1991) that allow targets of mobilization to link the frames with other things they know, experience, and/ or believe (Benford \& Snow, 2000; Snow et al., 1986). For example, in the context of a research partnership, participants might argue that a particular research finding leads to a particular course of action by linking that action with the district goals or mission as a way to persuade others of its value. But, frame alignment activities are always dependent upon how the individuals and groups respond, or what frame theorists call resonance (Snow et al., 1986; Williams \& Kubal, 1999). Resonance of a particular frame is the degree to which it is able to create a connection or strike a "deep responsive chord" (Binder, 2002, p. 220) with others in ways that motivate them to act or support a decision.

Achieving resonance may be especially challenging when participants come from different cultural worlds, as they do in the case of researchpractice partnerships. Just as in trading zones, frame resonance requires that participants develop ways of framing problems and solutions that communicate across these different worlds so that the social problems identified and the solutions proposed by teams "make sense" to one another. Furthermore, problem framings can be contested. Ways of framing the problem or arguments for a solution can be challenged as others put forth alternative portrayals of the situation or alternative paths to pursue (called counter-frames), often with different implications for roles, responsibilities, and resources (Benford \& Snow, 2000; Stone, 1988). Finally, status and authority also play a role. People with different levels of status and authority have differential influence in the negotiation about the meaning and implications of research findings, shaping the dynamics of interaction and the degree to which definitions of the problem and arguments for solutions are persuasive (Coburn, 2006; Coburn et al., 2008). 


\section{PROBLEM FRAMING IN THE PARTNERSHIP FOR DISTRICT REFORM}

The Partnership for District Reform (PDR) was a foundation-funded initiative that brought together an external research organization with a diverse, midsize urban school district to foster the development of the district as a learning organization, with the goal of creating the conditions for evidence-based practice in support of district-wide instructional improvement. The collaborative work in the initiative called for district and external partners to collaboratively identify problems and develop and implement solutions that would be informed by research but adapted to local conditions and capacities. This approach emphasized the importance of both research and clinical knowledge for solving the problems the district faced. It was to be a partnership where diverse forms of knowledge were valued and differences of opinion were adjudicated with reference to evidence. The external organization and the district worked to identify key areas of need for the district, focusing initially on redesigning the district's professional development offerings in mathematics and literacy, creating instructional frameworks in literacy and mathematics, developing a new approach to leadership development, and working to strengthen connections between the research office and the office of curriculum and instruction.

As we show using excerpts from this case study of the PDR led by the second author, the dynamics of problem framing within this partnership were shaped significantly by changing relations of status and authority among the different partners. The case illustrates that even when partners intend-as is characteristic of DBIR — to jointly negotiate problems in a way that reflects the views of diverse stakeholders, not all viewpoints resonate with or have equal sway over participants and the direction of the work. The analysis draws upon interviews with members of the central office, union officials, representatives from PDR, and other external consultants, as well as upon observations of planning meetings, professional development, and researcher-collected artifacts that were related to instructional decision making during the time of the study. A key focus of the analysis presented here was the role of authority and status in shaping the framing dynamics within key activities of the partnership.

A good example of an activity that illustrates how frames and frame dynamics can shape problem formulation and the search for solutions was evident in discussions related to the partnership's efforts to design summer professional development in literacy for the district. A research center member, authorized by the superintendent, led the process. This team member hired a mix of academics and former and current practitioners to work with district professional development staff to plan a 
series of weeklong summer institutes. The different participants, however, had different conceptions of the problems to be addressed and proposed different strategies for professional development that aligned with how they framed the specific problems to be addressed.

The alternate conceptualizations of problems and solutions are reflected well in these quotations from different participants in the collaborative design effort. One district professional development staff member commented:

The University doesn't understand our audience and . . . [doesn't] realize that this has to be concrete, real, practical, take it tomorrow and use it, really use. And the University is really good at making you think about what you're doing and reflect, but we wanted more real experiences for the institute that teachers could model their instruction after, and not so much heady thinking time, but more: This is a technique. This is a method. This is an approach. This is the way. This is a model of how you would do this strategy. (Coburn et al., 2008, p. 380)

By contrast, one of the outside professional development partners argued for a different approach to professional development:

[It] needs to be a thoughtful and careful combination of talking about hard issues in reading instruction and something useful. By useful, I mean it could be ways to look at your classroom data or ways of looking at texts to determine the appropriate level for text selection. But in doing the useful things, [you] need to tie it back to why these things are important and underlying conceptual issues so it's not just: This is what you need to do. (Coburn et al., 2008, p. 380)

These two different conceptualizations can be interpreted as offering competing diagnostic and prognostic frames for organizing the joint work of the partnership. For the district staffer, the "problem" is framed as the researchers' approach to professional development, that is, its emphasis on reflection and abstract ideas. The solution this staffer proposes is to provide a "technique . . . a method . . . an approach" that makes concrete what should be done in the classroom. The outside partner framed the problem as "issues in reading instruction" and utility. Like the district staffer, the outside partner called for concrete strategies, but also endorsed the abstract approach called for by the university partner, emphasizing the need to "tie it back to why these things are important."

These alternative conceptualizations of how to organize professional development directly conflicted with one another, and the team did 
not come to agreement on its focus and organization. The participants were uncertain as to who was supposed to take the lead in design and no agreement about the authority relationship between the district staff and external consultants emerged. Ultimately, the senior member of the research center-who had informal authority-stepped in, authorized the district professional development staff to take the lead, and scaled back the participation of external partners. From that point on, the external partners moved into a more traditional consultant role, providing feedback at the request of the district professional development staff and stepping in to give a talk during one segment of the summer professional development.

In this instance, the conflict was diffused and tensions eased, and the work was able to move forward, though it is important to note that from the standpoint of DBIR, this case illustrates the challenges that characterize the negotiation of problems and identification of solutions to those problems. In the above and other episodes, district leaders and external partners often found that they had differing ideas about the nature of the problem in the district and appropriate steps to address it. When differences of opinion emerged-as they often did-researchers and district leaders framed and reframed their ideas for their work together, attempting to subtly and not-so-subtly persuade one another about the appropriate steps to take to move forward. This negotiation was influenced in profound ways by relations of status and authority.

For their part, district leaders were more likely to have formal and informal authority, since those at the upper levels of the district had authority to make key decisions about strategic directions. Researchers and other external partners were more likely to have status, sometimes based in their perceived academic expertise, but often based on their prior role as practitioner. Some in the partnership-both external partners and frontline district personnel-had neither status nor authority in the negotiations. People with different levels of status and authority had different tools for persuasion at their disposal, and these both mattered for who was able to influence the direction of collaborative work.

Those with both authority and status were most successful in influencing the direction of collaborative work. We judged success by the degree to which others in a group took up and argued for a given position as their own (a key indicator of resonance) or the degree to which the frame shifted the central terms or direction of the debate. For example, early in the discussion about the summer institute, the external partners argued for a strategy of depth, suggesting that the district could make use of its resources by focusing more intensively on a subset of its schools. However, the superintendent-who had formal authority, but also was accorded status by insiders and outsiders alike-offered a counter frame. She argued 
that all schools should be included in the professional development initiative. She justified this approach by drawing on recent research on the importance of systemic approaches to instructional improvement and argued that what the district really needed was a uniform approach to instruction. She contended that including all schools in the initiative would best foster a uniform approach to instruction that would meet the needs of the district's highly mobile student population. This argument was persuasive to both insiders and outsiders involved in this decision point, who were generally familiar with and supportive of the notion of systemic reform. As an indicator of the resonance of this argument, insiders and outsiders alike repeated this logic to one another in subsequent conversations. Ultimately, the summer professional development institutes were designed to include teams from every school in the district.

Those who had both status and authority were successful in persuading others, in part because they were able to couple their framing activity with other strategies-like shaping who participated in deliberation and setting the agenda for those meetings-that appeared to bring power to their framing. In all but one decision point that involved individuals with both status and authority, prognostic frames put forth by these individuals generated resonance with others, shaping the direction of the joint work in consequential ways. Those with status and authority also used their authority to dictate the direction of collaborative work (rather than persuade others of its merit), but tended to use this approach sparingly, relying instead on the power of their persuasion.

Other configurations of status and authority were associated with different levels of influence over the direction of joint work. Like those with status and authority, those with status but not authority (usually external researchers, but not always) also focused heavily on framing and counterframing to persuade others of their point of view. However, those with status alone were not nearly as successful in using framing to persuade others as those who possessed both status and authority. Furthermore, they were most successful when they were engaged in collaboration with others who had similar beliefs about what constitutes good instruction or high-quality professional development. Those with authority but not status tended to use authority alone to promote their position, perhaps because they tended to be unsuccessful when they used persuasion alone. For example, when the assistant superintendent for elementary schools was unsuccessful at persuading others in the cabinet or the team designing the institute to include attention to a computerized tutoring system in the summer institute, she ordered the institute team to include one half-day devoted to the system. Importantly, those with authority were most likely to engage in this set of tactics when they had quite different beliefs about the appropriate way for the initiative to go than others in 
the collaborative group. Moreover, individuals who used their authority in this way were quite successful in shaping the direction of the collaborative work: direct uses of authority were successful in shaping the direction of the work in every decision point where they were used. Finally-and not surprisingly-those without authority or status had little influence over frames that were adopted.

This case illustrates how a focus on frames and framing dynamics can help to account for both successes and failures in partnerships' efforts to formulate problems to be addressed through joint work and to collaboratively design solutions to those problems. Frames can and do diverge, and in some cases, the frames suggest that particular partners and their perspectives are part of the problem to be solved. These competing frames mean that conflict is likely, and within conflict, authority relations are particularly likely to be in play. Status matters too, but in this instance at least, authority relations were more influential than status, in that those with authority had a much greater range of strategies for influencing the direction of collaborative work and felt free to use them.

\section{FUTURE DESIGN-BASED IMPLEMENTATION RESEARCH ON TOOLS AND PRACTICES OF NEGOTIATION}

Both of these sets of analytic tools - the metaphor of a trading zone and the concept of framing - can, in our view, help us interpret the dynamics of research-practice partnerships. While each sheds light on a different aspect of dynamics, there are some ways, too, that the two sets of tools can be used in concert with one another to illuminate additional dynamics of partnerships. For example, we can view the creation of pidgin languages within partnerships as a kind of "frame producing" activity, one in which other frames are used as resources. Likewise, we can think of boundary spanners as people who are fluent in appropriating different frames depending on their audience, frames that are likely to resonate with those audiences. And, we can think of the adoption of pidgin languages by people who do not occupy the trading zone (i.e., those partners who collaborate most intensively with one another) as evidence of "resonance" with partnership goals and strategies, and thus as an indicator of the success of a partnership. Failure, by contrast, might be indicated by moves to close off negotiation over frames, and by the elimination of trading zones in which collaborative work can take place.

We also believe that the case study research can inform a program of design-based implementation research in this area that aims not just at documenting, but also at improving the quality and effectiveness of negotiation within partnerships. In articulating this program, we draw on the experience of the third author in forming and maintaining partnerships 
from the standpoint of district leaders. The areas we articulate below are linked directly to challenges he has experienced, as well as to the analytic tools we have introduced and that have been useful for studying negotiation in partnerships. We envision these as general strategies for improvement and-in keeping with DBIR's focus on research-potential objects of research within research-practice partnerships. The five key challenges that organize this section are

- Defining clear roles and lines of authority for action,

- Building boundary practices for collaborative design,

- Anticipating the "counter-normative" in establishing the partnership,

- Involving people at multiple levels of the system, and

- Constructing multiple frames for the work for use in different settings.

\section{DEFINING CLEAR ROLES AND LINES OF AUTHORITY FOR ACTION}

In the case of PDR described above, the partnership struggled to find a common focus when clear roles and lines of authority were absent. It was not until the superintendent gave informal authority to a leader from outside the organization to design the summer institute that the partnership could get past its initial conflicts over how to frame the problems to be addressed by professional development. Developing clear roles for people to take on, and establishing lines of authority for action up front may be a way to prevent - or at least minimize the effects of-conflicts that lead to major impasses within partnerships. A challenge to doing so is anticipating who may be perceived as having credible expertise in the areas of joint work that are likely to become the focus of the partnership. Implementation research may help to identify local experts and sources of status and authority early on, to help align roles to better accomplish the team's goals.

\section{BUILDING BOUNDARY PRACTICES FOR COLLABORATIVE DESIGN}

Teams can organize joint work and address dynamics related to voice by building boundary practices together. It is particularly important that, in developing processes for collaboration, a design process makes explicit use of practices that are "native" to each culture to be beneficial in research-practice partnerships. It is critically important that participants in design projects believe that they are "building the plane and flying it, too," and not just "flying a plane someone else has built." There 
may need to be additional boundary practices aimed specifically at helping new collaborative partners enter and participate productively in the boundary zone. Implementation research might productively focus on how people join in these practices, as well as on who successfully is able to join in and get some footing within design conversations, to ensure the broadest participation in design possible.

\section{ANTICIPATING THE “COUNTER-NORMATIVE” IN ESTABLISHING THE PARTNERSHIP}

Because many of the roles in a research-practice partnership will be unfamiliar to both researchers and practitioners, it is critical for stakeholders from both cultures to anticipate what will be counter-normative-that is, go strongly against the grain of the norms and cultural expectations for action-in the partnership. For researchers, this could mean anticipating how the repurposing of a curriculum by a small team of outsiders and insiders might be perceived in a given district, or in the context of a large-scale implementation of a web-based curriculum portal for teachers (as in the case of the UW-Bellevue partnership). It may also mean preparing graduate students on projects for different kinds of roles they might play-not just in formulating research plans and implementing them, but also in establishing working relationships with teachers and district staff and in co-designing innovations.

For practitioners, anticipating the counter-normative might mean working to make explicit to fellow practitioners the purposes for engaging a researcher, as well as working out the time frames or deadlines that would be important for meeting district goals. The syncing of timescales between researchers and practitioners is especially difficult to accomplish, as researchers typically produce research much more slowly than practitioners need it to inform their practice. Implementation research may be particularly critical for collecting data on the perceived timeliness of research for practitioners, as well as on participants' perceptions of their new roles.

\section{INVOLVING PEOPLE AT MULTIPLE LEVELS OF THE SYSTEM}

It is common for many partnerships-if they last long enough-to encounter high levels of turnover. Within school districts, the tenure of superintendents is typically short, and curriculum leadership can change at fairly short intervals as well, whereas teachers may stay with a project and a school for longer periods of time. Given these organizational realities, the involvement and support of people at all levels of the school system is important. This is, in part, because involving people whose positions are more stable than others can help partnerships maintain a history of 
the joint work in the form of participants who can recall specific decisions and rationales for them. In addition, involving people at multiple levels of the system creates potentially more durable buy-in to partnership work. Likewise, districts may need to develop multiple faculty or research partners as collaborators, since researchers themselves may change or face difficulty in garnering funding for their involvement (see also Sabelli \& Dede, 2013).

\section{CONSTRUCTING MULTIPLE FRAMES FOR THE WORK FOR USE IN DIFFERENT SETTINGS}

A final recommendation grows from the practical experience of many who have been successful in forming and maintaining productive research-practice partnerships and from an analytic focus on frames. Successful builders of partnerships tend to build bridges more than halfway across the cultural divide that separates researchers from practitioners. In other words, a good researcher can talk about problems of practice using language that a teacher or coach might use, and does not talk just in ways that are recognizable to other researchers. Likewise, a successful practitioner who builds partnerships can frame issues in ways that a researcher will understand and appreciate. It may be that any given partnership has only one person who knows and can use these different frames, but it is potentially even more valuable if both a researcher and a practitioner can do so. Some partnerships, like SERP Institute (see Donovan et al., 2013), create boundary-spanning positions within their infrastructures that are intended to facilitate just this process.

The work of boundary spanners is different at the beginning of partnerships than when a partnership is mature. At first, the effort that boundary spanners make to "translate" across frames is focused among those people who are most intensively involved in the collaboration. But, as the work matures-and as the partnership brings new policies or programs to scale-then the work becomes more externally focused on convincing researchers and practitioners to allocate and activate the resources that may be needed for implementation. The work still involves being fluent in multiple frames, but its purpose shifts in significant ways that, as a field, we do not yet know well how best to support.

\section{CONCLUSION}

The work of forming and maintaining partnerships is both challenging and important within DBIR. Multiple ways of examining the process of partnership formation are needed. We see a role for bringing together two frameworks we have presented in this process to support both goals. 
We also see a need for implementation research that focuses on designs for improving the processes of negotiating problems of practice, such that these processes are more democratic and attuned carefully to dynamics of status and authority. We do not envision a world where all participants in a research-practice partnership share the same worldview or interact without concern for issues of status and authority. However, we do believe that ongoing research on strategies for improving the joint negotiation of problems of practice is important to DBIR's development and can help improve the functioning of partnerships.

\section{References}

Akkerman, S. F., \& Bakker, A. (2011). Boundary crossing and boundary objects. Review of Educational Research, 81(2), 132-169.

Beach, K. (2003). Consequential transitions: A developmental view of knowledge propagation through social organizations. In T. Tuomi-Gröhn \& Y. Engeström (Eds.), Between school and work: New perspectives on transfer and boundary crossing (pp. 39-62). London: Elsevier.

Benford, R. D., \& Snow, D. A. (2000). Framing processes and social movements: An overview and assessment. Annual Review of Sociology, 26, 611-639.

Binder, A. J. (2002). Contentious curricula: Afrocentrism and Creationism in American public schools. Princeton, NJ: Princeton University Press.

Bransford, J. D., Brown, A. L., \& Cocking, R. R. (1999). How people learn: Brain, mind, experience, and school. Washington, DC: National Academy Press.

Coburn, C. E. (2006). Framing the problem of reading instruction: Using frame analysis to uncover the microprocesses of policy implementation. American Educational Research Journal, 43(3), 343-379.

Coburn, C. E., Bae, S., \& Turner, E. O. (2008). Authority, status, and the dynamics of insider-outsider partnerships at the district level. Peabody Journal of Education, 83, 364399.

Coburn, C. E., Honig, M. I., \& Stein, M. K. (2009). What's the evidence on districts' use of evidence? In J. D. Bransford, D. J. Stipek, N. J. Vye, L. M. Gomez, \& D. Lam (Eds.), The role of research in educational improvement (pp. 67-87). Cambridge, MA: Harvard Education Press.

Donovan, M. S., Snow, C., \& Daro, P. (2013). The SERP approach to problem-solving research, development, and implementation. National Society for the Study of Education Yearbook, 112(2), 400-425.

Engeström, Y., Engeström, R., \& Karkkainen, M. (1995). Polycontextuality and boundary crossing in expert cognition: Learning and problem solving in complex work activities. Learning and Instruction, 5(4), 319-336.

Galison, P. (1997). Image and logic: A material culture of microphysics. Chicago, IL: University of Chicago Press.

National Research Council. (1996). National Science Education Standards. Washington, DC: National Academy Press.

National Research Council. (1999). How people learn: Brain, mind, experience, and school. Washington, DC: National Academy Press.

National Research Council. (2000). Inquiry and the National Science Education Standards. Washington, DC: National Academy Press. 
Penuel, W. R., Fishman, B. J., Cheng, B., \& Sabelli, N. (2011). Organizing research and development at the intersection of learning, implementation, and design. Educational Researcher, 40(7), 331-337.

Penuel, W. R., Roschelle, J., \& Shechtman, N. (2007). The WHIRL co-design process: Participant experiences. Research and Practice in Technology Enhanced Learning, 2(1), 51-74.

Sabelli, N., \& Dede, C. (2013). Empowering design-based implementation research: The need for infrastructure. National Society for the Study of Education Yearbook, 112(2), 464 -480 .

Schneider, A., \& Ingram, H. (1993). Social construction of target populations: Implications for politics and policy. American Political Science Review, 87(2), 334-347.

Schwartz, D. L., Lin, X., Brophy, S., \& Bransford, J. D. (1999). Toward the development of flexibly adaptive instructional designs. In C. M. Reigeluth (Ed.), Instructional design theories and models: A new paradigm of instruction theory (Vol. 2, pp. 183-213). Mahwah, NJ: Erlbaum.

Snow, D. A., \& Benford, R. D. (1988). Ideology, frame resonance, and participant mobilization. International Social Movement Research, 1, 197-217.

Snow, D. A., Rochford, E. B., Jr., Worden, S. K., \& Benford, R. D. (1986). Frame alignment processes, micromobilization, and movement participation. American Sociological Review, 51, 464-481.

Star, S. L., \& Griesemer, J. R. (1989). Institutional ecology, "translations" and boundary objects: Amateurs and professionals in Berkeley's Museum of Vertebrate Zoology, 1907-1939. Social Studies of Science, 19(3), 387-420.

Stone, D. A. (1988). Policy paradox and political reason. Glenview, IL: Scott Foresman.

Wenger, E. (1998). Communities of practice: Learning, meaning, and identity. Cambridge, MA: Cambridge University Press.

Williams, R. H., \& Kubal, T. J. (1999). Movement frames and the cultural environment: Resonance, failure, and the boundaries of the legitimate. Research in Social Movements: Conflicts and Change, 21, 225-248.

Zucker, L. (1991). Postscript: Microfoundations of institutional thought. In W. W. Powell (Ed.), The new institutionalism in organizational analysis (pp. 103-106). Chicago: University of Chicago Press.

WILLIAM PENUEL is a professor of educational psychology and learning sciences at the University of Colorado Boulder. His research focuses on teacher learning and organizational processes that shape the implementation of educational policies, school curricula, and afterschool programs. Recent publications include "Large-scale science education intervention research we can use" (2012, Journal of Research in Science Teaching) with Barry Fishman; "Preparing teachers to design sequences of instruction in earth science: A comparison of three professional development programs" (2011, American Educational Research Journal) with Lawrence P. Gallagher and Savitha Moorthy; and "Using large-scale databases in evaluation: Advances, opportunities, and challenges" (2011, American Journal of Evaluation) with Barbara Means. 
CYNTHIA COBURN is a professor at the School of Education and Social Policy, Northwestern University. Her research focuses on the relationship between instructional policy and teachers' classroom practices in urban schools. Recent publications include Research and practice in education: Building alliances, bridging the divide (2010, Rowman \& Littlefield) with Mary Kay Stein; "Research on data use: A framework and analysis," (2011, Measurement: Interdisciplinary Research $\mathcal{E}$ Perspective) with Erica Turner; and "Reading coaches and the relationship between policy and practice” (2012, Reading Research Quarterly) with Sarah Woulfin.

DAN GALLAGHER is the Science Program Manager for Seattle Public Schools. He works to build teams of people with complementing expertise and resources by forming collaborations inside and outside of school districts. Through multiple regional and national partnerships, he has developed science curricula and professional development programs for a number of high school and college courses. 